\title{
GERAÇÃO DE VALOR NO ENSINO SUPERIOR PRIVADO: UMA ANÁLISE DO PLANO DE DESENVOLVIMENTO INSTITUCIONAL (PDI)
}

\author{
GENERATION OF VALUE IN PRIVATE HIGHER EDUCATION: \\ AN ANALYSIS OF INSTITUTIONAL DEVELOPMENT PLAN \\ (IDP)
}

\section{GENERACIÓN DE VALOR EN LA ENSEÑANZA SUPERIOR PRIVADA: UN ANÁLISIS DEL PLAN DE DESARROLLO INSTITUCIONAL (PDI)}

\author{
Claudio Marcos Maciel da Silva \\ Doutor em Administração pela Universidade do Grande \\ Rio (UNIGRANRIO), Brasil / Professor da \\ Universidade Estácio de Sá, Brasil \\ professorclaudiomaciel@gmail.com \\ José Francisco de Carvalho Rezende \\ Doutor em Administração pelo Instituto de Pós- \\ Graduação e Pesquisa em Administração da \\ Universidade Federal do Rio de Janeiro (COPPEAD), \\ Brasil / Professor e Pesquisador do Programa de \\ Mestrado em Administração do Ibmec, Brasil \\ rezende.jf@gmail.com
}

\author{
Contextus \\ ISSNe 2178-9258 \\ Organização: Comitê Científico Interinstitucional \\ Editor Científico: Carlos Adriano Santos Gomes \\ Avaliação: double blind review pelo SEER/OJS \\ Recebido em 21/05/2017 \\ Aceito em 08/12/2017 \\ $2^{\mathrm{a}}$ versão aceita em $18 / 12 / 2017$
}

\section{RESUMO}

O objetivo desta pesquisa é a de verificar a possibilidade de estabelecer uma hierarquia de criação de valor das instituições de ensino superior (IES) com base nos direcionadores de capital intelectual e capital financeiro presentes no plano de desenvolvimento institucional (PDI) de diferentes IES privadas. Para isso, foi necessário identificar elementos pertencentes ao capital intelectual e ao capital financeiro nos PDIs de diferentes IES. Foram analisados 24 PDIs pertencentes às principais IES privadas localizadas no estado do Rio de Janeiro. Os resultados apontam para a predominância de direcionadores como a titulação docente e regime de trabalho, infraestrutura, responsabilidade socioambiental, receita e orçamento.

Palavras-chave: Instituições de ensino superior. Capital intelectual. Plano de Desenvolvimento Institucional. Gestão Universitária. Criação de Valor.

\section{ABSTRACT}

The purpose of this research is to verify the possibility of establishing a hierarchy of value creation for higher education institutions (HEIs) based on the so-called drivers of intellectual and financial capital informed on the institutional development plans (IDPs) of different private HEIs. For this, it was necessary to identify the elements belonging to the intellectual and financial capital on the IDPs of different HEIs. We analyzed 24 IDPs belonging to the main private HEIs located in Rio de Janeiro state. The results point to a predominance of drivers such 
as academic degree and work regime, infrastructure, socio-environmental responsibility, revenue and budget.

Keywords: Higher education institutions. Intellectual capital. Institutional development plan. University management. Value creation.

\section{RESUMEN}

El objetivo de esta investigación es la de verificar la posibilidad de establecer una jerarquía de creación de valor de las instituciones de enseñanza superior (IES) con base en los directores de capital intelectual y capital financiero presentes en el plan de desarrollo institucional (PDI) de las diferentes IES privadas. Para ello, fue necesario identificar elementos pertenecientes al capital intelectual y al capital financiero en los PDI de diferentes IES. Se analizaron 24 PDI pertenecientes a las principales IES privadas en el estado de Río de Janeiro. Los resultados apuntan a la predominancia de directores como la titulación docente y régimen de trabajo, infraestructura, responsabilidad socio-ambiental, ingresos y presupuesto.

Palabras clave: Instituciones de enseñanza superior. Capital intelectual. Plan de Desarrollo institucional. Gestión universitaria. Creación de valor.

\section{INTRODUÇÃO}

Nos últimos anos, verificou-se uma série de estudos sobre a possibilidade de identificar, mensurar, gerir e controlar o capital intelectual em instituições de ensino superior (IES) (CRANFIELD; TAYLOR, 2008; RAMIREZ CORCOLES, 2013; RAMIREZ CORCOLES; GORDILLO, 2014; SILVESTRI; VELTRI, 2011). Essa preocupação, aliada com o gerenciamento do capital financeiro (capital físico mais capital monetário), tornou imprescindível a busca pela geração de valor na gestão das IES.

O conceito de valor é definido por Roos et al. (1997) como a soma entre os capitais financeiro e intelectual. $\mathrm{O}$ financeiro é composto pelos ativos físicos e monetários, já reconhecidos pela contabilidade. Por sua vez, o intelectual abrange o capital humano, o estrutural e o relacional

(SAINT-ONGE; ARMSTRONG, 2004; SULLIVAN, 2000; DZINKOWSKI, 2000).

Dentre as experiências observadas sobre a importância do capital intelectual na gestão das instituições de ensino, destaca-se a experiência austríaca de elaboração do Relatório de Capital Intelectual das Instituições de Ensino Superior (MACHADO, 2008; SANCHEZ; ELENA; CASTRILLO, 2009; CORCOLES, 2010). É um documento obrigatório de apresentação das IES para o governo e sociedade, de acordo com regulamento WBV, BGBl. II Nr.216/2010. Deve, de acordo com a lei, ser "a apresentação holística de avaliação e comunicação de ativos intangíveis, os processos de desempenho e seus efeitos e como é a base qualitativa e quantitativa". 
No Brasil, apesar de não haver nenhum órgão regulador que exija um relatório de capital intelectual, apresentamse informações pertinentes à estrutura das IES através do Plano de Desenvolvimento Institucional (PDI). No entanto, Awad (2010) desenvolveu o mapeamento do capital intelectual na Universidade de Passo Fundo, tendo como referência o Modelo de Navegador de Stewart (1998), que monitora os principais direcionadores pertencentes ao capital intelectual.

A questão desta pesquisa é a de verificar a possibilidade de estabelecer uma hierarquia de criação de valor das IES com base nos direcionadores de capital intelectual e capital financeiro presentes no PDI de diferentes IES privadas.

\section{REFERENCIAL TEÓRICO}

Awad (2010) desenvolveu o mapeamento do capital intelectual da Universidade de Passo Fundo tendo como referência o Modelo de Navegador de Stewart (1998), que o subdivide em três: capital humano, estrutural e relacional.

Silva et al. (2014) adaptaram os itens pertinentes a cada dimensão de modo a validar a importância deles para construir cada dimensão do capital intelectual através de entrevistas a coordenadores de cursos de Administração no Rio de Janeiro. O resultado encontrado foi que não só a relevância dos itens irá diferir de acordo com a natureza jurídica da IES (pública ou privada), mas também o perfil de renda familiar de seu corpo discente.

De forma a identificar elementos capazes de gerar valor, é necessária compreender o capital intelectual - e suas respectivas dimensões $-\quad$ e $\quad$ o capital financeiro.

\subsection{Capital humano}

De acordo com Francisco (2011, p. 88), "os conhecimentos, habilidades e atitudes dos professores consolidam as sistemáticas heurísticas vinculadas à construção do conhecimento na organização". Um docente não fica limitado a mero instrutor, mas figura como agente importante na elaboração de projetos político-pedagógicos, na construção de conteúdos curriculares e planos de ensino e no compartilhamento das melhores práticas de ensino.

A gestão do capital humano docente pode qualificar uma instituição de ensino, porém é difícil mensurar o valor agregado gerado pelo conhecimento. Pelas avaliações institucionais do MEC o corpo docente é avaliado de acordo com sua titulação, regime de trabalho, tempo de docência, 
experiência profissional e produção científica.

As notas obtidas pelo ENADE (Exame nacional de desempenho dos estudantes) através das métricas do Conceito Preliminar de Curso (CPC) e do Índice Geral de Cursos da Instituição de Educação Superior (IGC), também consideram a titulação e experiência docente.

A experiência complementa a formação do docente como forma de legitimar a sua presença em sala de aula. Esta formação, paradoxalmente, não está restrita a titulação acadêmica - Mestrado e Doutorado. Para muitos cursos (principalmente os da área de gestão), um docente com experiência de mercado, tendo já ocupado cargo de gestão é mais relevante do que a sua formação acadêmica.

A produção científica envolve a elaboração de resenhas, pensatas e artigos para submissão e posterior participação em eventos, congressos, seminários, bem como na autoria/coautoria em revistas reconhecidas pela comunidade acadêmicas, preferencialmente as indexadas pelo sistema webqualis. Entretanto esta capacidade de produção científica, para alguns entrevistados está vinculada ao apoio institucional por parte da IES.
No modelo austríaco de capital intelectual (WBV, BGBI. II Nr. 216/2010) estão incluídas as participações dos membros da IES em gestão de órgãos de conselhos científicos, podendo ser editores ou organizadores de revistas científicas. Este item demonstra a preocupação do governo com a inserção da Universidade na comunidade científica internacional.

As atividades operacionais ligadas ao desempenho do corpo técnicoadministrativo podem conceber valor a IES através da eficiência de suas atividades tais como matrícula, secretaria, atendimento ao aluno, suporte ao corpo docente, etc. A capacitação docente abrange o treinamento e capacitação do docente por cursos e incentivo de especialização em programas de pós-graduação lato sensu e stricto sensu.

Também no relatório de capital intelectual das universidades austríacas é valorizado o grau de internacionalização da IES dentro do capital humano. Esse grau de internacionalização abrange intercâmbios realizados por professores e alunos no exterior, bem como a participação em eventos e atividades fora da IES. Esse item pode ser um relevante indicador para IES privadas destinadas a alunos de alta renda, uma vez que um alto grau de internacionalização de sua comunidade científica pode corresponder à qualidade de ensino. 


\subsection{Capital estrutural}

$\mathrm{Na}$ identificação dos construtos do capital estrutural, Silva et al. (2014) apontam para os itens filosofia gerencial, infraestrutura, os seus processos de gestão, sistemas de informação e as tecnologias aplicadas.

A filosofia gerencial é um dos itens mais importantes sobre o capital estrutural. Entretanto, a sua definição é ambígua, podendo abranger tanto a parte administrativa quanto a pedagógica de uma IES. Quando a abordagem é administrativa, metas e objetivos são descritos como qualquer outra empresa. Por outro lado, quando pedagógica, os projetos pedagógicos de curso (PPCs) são citados pelos respondentes. Tais projetos servem de roteiro para o cumprimento de requisitos mínimos estabelecidos pelo Ministério da Educação (MEC) para o funcionamento dos cursos.

De forma a operacionalizar essa filosofia gerencial, os processos de gestão, quando bem aplicados, podem ser um elemento gerador de valor em uma IES. Envolvem o mapeamento de procedimentos administrativos de forma a verificar quais seriam as melhores práticas de gestão. Também incluem as reuniões com o setor acadêmico, onde são discutidos com coordenadores de curso o cumprimento de suas metas e métricas. Entretanto, o uso excessivo de indicadores pode causar um efeito reverso na gestão da IES.

Tachizawa e Andrade (2006) trabalham com a concepção de que os processos de gestão de uma instituição de ensino superior são realizados a partir da transformação de insumos em produtos. Segundo o autor, os insumos correspondem ao corpo docente, projeto pedagógico e recursos materiais, tecnológicos e financeiros. Já o processo de produção consiste no processo ensino-aprendizagem e nos sistemas de informação de apoio ao aluno. Por fim, o produto final seriam os egressos da instituição.

Embora o autor não faça a separação dos processos administrativos e acadêmicos, a importância da contribuição se reporta à importância do mapeamento de processos, vinculados a um Centro de Serviços Compartilhados (CSC). Este pode auxiliar a elaboração de indicadores de desempenho administrativos, gerando metas a serem alcançadas.

O Balanced Scorecard pode ser uma importante ferramenta de controle de gestão de processos administrativos e pedagógicos em uma instituição de ensino (HLANDCHANKO,2015). Hékis (2010) apresenta o estudo de caso da Universidade Estácio de Sá que estruturou suas metas tendo como referência as dimensões 
financeira, clientes, processos internos e aprendizado e crescimento. Para isto, a IES teve que reorganizar-se administrativamente com um Modelo de Ensino baseado na implementação de um Centro de Ensino pedagógico com objetivo de criar e padronizar currículos nacionais dos seus cursos, bem como criar uma Central de Serviços Compartilhados (CSC) de forma a monitorar e padronizar os seus processos administrativos.

As tecnologias aplicadas abrangem o impacto da informatização na gestão de uma IES. Tais tecnologias estão presentes nos diversos sistemas de informações no gerenciamento do banco de dados sobre matrícula, acompanhamento financeiro e desempenho acadêmico dos alunos.

Os sistemas de informação também podem agregar valor ao capital estrutural, considerando que, ao facilitar e reduzir tarefas administrativas, contribuem para o ganho de produtividade da instituição de ensino (GIANOTTI, 2004; REIS, Edson; REIS, Everson, 2013). Podemos usar como exemplo a melhoria das condições de atendimento de uma secretaria acadêmica, em virtude de um sistema de informação que auxilie na solução dos principais problemas dos alunos (acerto de notas, inclusão/exclusão de disciplinas, etc).

Ao estudarmos a possibilidade de os sistemas de informação se tornarem uma peça importante do capital estrutural, temos que considerar a hipótese de que os processos de gestão devem estar bem definidos. O sistema de informação, por si só, não se constitui em geração de valor, tampouco pode gerar uma vantagem competitiva. Em alguns casos, ela inclusive pode gerar uma deseconomia de escala, em virtude do alto custo de manutenção e pela falta de um mapeamento adequado de processos.

Pode-se destacar, como um exemplo do impacto do capital estrutural na área acadêmica, o fortalecimento do Ensino à Distância (EAD). Esta modalidade de ensino foi a que mais cresceu percentualmente nos últimos cinco anos (INEP, 2014). A possibilidade de ofertar cursos a um preço mais barato do que o presencial estimulou a captação de alunos provenientes da classe nova classe média, que ganhou 40 milhões de pessoas em sua composição no período de 2003 a 2011.

A tecnologia também pode estar presente em uma IES através de ferramentas educacionais que podem proporcionar ganhos de escala quando bem empregados, como por exemplo o ensino a distância. A interatividade tecnológica utilizada em sala de aula também pode ser um fator de diferenciação de qualidade da IES. 


\subsection{Capital relacional}

O capital relacional corresponde à relação entre uma organização e seus clientes. Grande parte dos autores considera o cliente como quem desempenha um papel de troca ou mesmo transação de produto/serviço em uma determinada organização. Entretanto, classificar o aluno como cliente é polêmico (SIRVANCI, 1996; RIZZO, 2010; VERGARA E AMARAL; 2010).

O cliente pode, com efeito, estar relacionado ao aluno como consumidor de produtos e serviços educacionais. Por outro lado, a concepção de cliente também pode estar direcionada à sociedade (governo, empresas), pois esta é que vai usufruir da formação de seus egressos. Ainda existe a possibilidade na inexistência de uma relação de clientela no setor educacional.

Como o modelo de gestão das IES é pautado na reprodução das práticas utilizadas em outros setores do ramo de serviços que trabalham com foco no cliente. Como o aluno é aquele quem paga pelo serviço, seria lógico, segundo esse paradigma, que este seja o cliente. Vergara e Amaral (2010) desenvolveram uma série de críticas da adequação deste pensamento para a gestão de instituições de ensino.

\section{A Imagem Institucional}

compreende o conjunto de esforços de construção de uma imagem positiva do curso junto ao mercado de trabalho e sociedade como um todo. A construção desta imagem institucional será gerenciada pela direção da IES. Em alguns casos, esta imagem é construída no reconhecimento da qualidade do ensino, seja pela tradição ou por avaliações positivas nos resultados dos seus egressos no Exame Nacional de Cursos (ENADE), amplamente divulgados pela imprensa. Em outros, a própria direção da IES investe maciçamente no marketing institucional de forma a fortalecer a marca do estabelecimento de ensino e assim, criar uma barreira à entrada para o crescimento do número de alunos em IES mais modestas.

As Alianças Estratégicas abrangem os acordos de cooperação com outras Instituições de Ensino, na maioria das vezes do exterior, convênios com empresas privadas visando a inserção de seus alunos no mercado de trabalho e aproximação com órgãos representativos de classe. Silva et al. (2014) observaram que dependendo da classe social de seus alunos, a política de alianças terá uma formatação diferente. Para IES com perfis de alunos de renda mais elevada, a parceria com outras IES estrangeiras é priorizada, promovendo a internacionalização de seus estudos. Por outro lado, IES com perfis de alunos de renda mais baixa priorizam a 
empregabilidade de seus alunos através de parceria com empresas e órgãos de classe profissional - como sindicatos e conselhos regionais.

A responsabilidade social e ambiental promovida pela IES também é importante para sua visibilidade junto à sociedade (CALDERÓN, 2006; BOLAN, MOTTA, 2007; REIS; BANDOS, 2012). As empresas estão sendo mais cobradas a adotarem uma postura de compromisso de gerar externalidades positivas. Não obstante, a direção das IES busca através de diversas iniciativas demonstrar também o seu comprometimento. As IES, independente de seu porte ou natureza jurídica, atuam através de programas de extensão universitária, muitas das vezes previstas no projeto pedagógico de cada curso.

A interação entre as diversas dimensões do capital intelectual também pode gerar valor para a IES. De certa forma, a integração entre professores e alunos em sala de aula pode combinar elementos do capital humano e do relacional, assim como um bom atendimento de secretaria pode ser facilitado na combinação de fatores entre o capital estrutural e o relacional.

\subsection{Capital financeiro}

O capital financeiro compõe-se dos itens que contribuem para o reforço do caixa de uma empresa. Para isso, serão analisados a receita da instituição de ensino, a sua política de contenção de custos, as previsões para o futuro contidas no plano estratégico, a capacidade de geração de novos negócios, a projeção de investimentos e o grau de descentralização administrativa

(TACHIZAWA; ANDRADE，2006; AWAD，2010; LUZ FILHO, 2016).

Considerando todos os itens descritos nestes estudos anteriores, a suposição a ser estudada nesta pesquisa é a de que tais elementos se encontram no Plano de Desenvolvimento Institucional (PDI), uma vez que este é o reflexo do planejamento estratégico de uma IES.

\section{PROCEDIMENTOS METODOLÓGICOS}

Trata-se de um estudo qualitativo com viés documental quanto aos meios (VERGARA, 2007), uma vez que utilizou como referência o documento oficial de planejamento estratégico de uma IES: o Plano de Desenvolvimento Institucional (PDI). 
Os construtos referentes ao capital intelectual encontrados nos PDIs serão agrupados nas dimensões capital humano, estrutural e relacional (STEWART, 1998).

A partir da comparação entre os relatórios de desempenho das universidades austríacas e do Plano de Desenvolvimento Institucional (PDI) das IES brasileiras, os seguintes direcionadores foram utilizados:

$\checkmark$ capital humano: titulação docente e regime de trabalho, produção científica, corpo técnico administrativo, experiência profissional, capacitação docente e atuação dos coordenadores de curso.

capital estrutural: filosofia gerencial, sistema de informações acadêmicas, tecnologia educacional, centro de serviços compartilhados (CSC) e infraestrutura.

$\checkmark$ capital relacional: responsabilidade socioambiental, acompanhamento do egresso, parceria com o mercado de trabalho, parceria com centros de pesquisa e imagem institucional.

$\checkmark$ capital financeiro: acompanhamento da receita, controle de custos, previsão de novos negócios, orçamento, descentralização financeira, investimentos.

Foi utilizado um recorte na pesquisa documental dos PDIs a partir das IES privadas localizadas no Estado do Rio de
Janeiro. Foram identificados 24 (vinte e quatro) Planos de Desenvolvimento Institucional, sendo destes, seis referentes a Universidades (IES A a F), quatro de centros universitários (IES G a J) e os demais de faculdades isoladas (IES K a W). Estas IES foram responsáveis por $74 \%$ do total de alunos que realizaram o ENADE no período 2012-2014 no Estado do Rio de Janeiro.

Com auxílio do software Atlas TI 7.0, foram identificados elementos que caracterizam a citação do capital intelectual e financeiro das IES. Cabe reforçar que esta presença, não significa que a IES esteja gerenciando adequadamente estes recursos intangíveis.

De forma a identificar o tipo de informação contido no PDI foi estabelecida uma escala numérica adaptada do modelo de Guthrie et al. (1999) aplicado em relatórios gerenciais de empresas de capital aberto. Este modelo classificava o item como: não encontrado, apareceu de forma narrativa, apareceu de forma numérica e apareceu de forma monetária.

A escala adotada foi adaptada de forma a adequar-se às características do PDI, que inclui tanto fatos ocorridos, quanto de informações que correspondem a meras intenções. Assim foi estabelecido uma escala de 0 a 5, descrito no Quadro 1: 
Quadro 1 - Sistema de codificação numérica

\begin{tabular}{|c|c|c|}
\hline Níveis & Característica & Valor \\
\hline 0 & Não Citado & Não Apresenta \\
\hline 1 & $\begin{array}{c}\text { Incidental, Casuístico, indícios de geração de } \\
\text { valor }\end{array}$ & Ocasionalmente Executado \\
\hline 2 & Comunicação de valor gerado ou a gerar & $\begin{array}{c}\text { Minimamente planejado e } \\
\text { acompanhado }\end{array}$ \\
\hline 3 & Fundamentado Efetivo & Padronizado e Avaliado \\
\hline 4 & Gerenciado, Otimizado & Comparado e Valorado (R $\$)$ \\
\hline 5 & Pervasivo, Alinhado & $\begin{array}{c}\text { Otimizado e Reconhecido } \\
\text { externamente }\end{array}$ \\
\hline
\end{tabular}

Fonte: adaptado de Guthrie et al. (2004).

4 RESULTADOS E DISCUSSÕES

Na dimensão do capital humano, destaca-se a divulgação da titulação docente e do regime de trabalho. Por exigência do relatório, a IES informa que percentual de docentes pertencentes ao seu quadro possui titulação de mestrado/doutorado e também o tempo dedicado para atuar na instituição desde horista até professor de tempo integral.

Por ser item obrigatório na apresentação do PDI, a infraestrutura foi mais citada pelas IES. No entanto, cabe destacar a filosofia gerencial. A sua concepção pode abranger tanto a parte administrativa quanto a pedagógica de uma IES. Quando a abordagem é administrativa, as metas e objetivos são valorizados como qualquer empresa do setor privado. Está presente nos PDIs de IES controladas por grupos educacionais. Por outro lado, quando a abordagem é pedagógica, destacam-se os princípios contidos no projeto pedagógico de curso (PPCs) - como, por exemplo, uma faculdade isolada de Medicina.

Quanto ao capital relacional, destacam-se os programas de responsabilidade social desenvolvidos pela IES. As empresas estão sendo mais cobradas a adotarem uma postura de compromisso para gerar externalidades positivas. As IES, independentemente de seu porte ou natureza jurídica, atuam através de programas de extensão universitária, muitas das vezes previstas no projeto pedagógico de cada curso.

O capital financeiro corresponde à integração entre os ativos físicos e monetários, já reconhecidos pela contabilidade. Esse capital financeiro é alcançado através do gerenciamento de itens que contribuem para a valorização patrimonial e para o reforço do caixa de uma empresa (STEWART, 1998). No caso de uma IES privada, a realidade brasileira aponta para a sustentabilidade financeira pautada na receita das mensalidades pagas pelos alunos (CASTRO, 2013). 
Tabela 1 - Número de IES que abordam os direcionadores do capital intelectual e financeiro por níveis de citação

\begin{tabular}{|c|c|c|c|c|c|c|c|c|}
\hline Direcionadores da Criação de Valor & $\overline{\mathbf{D}}$ & $\begin{array}{c}\text { Nível } \\
0\end{array}$ & $\begin{array}{c}\text { Nível } \\
1\end{array}$ & $\begin{array}{c}\text { Nível } \\
2\end{array}$ & $\begin{array}{c}\text { Nível } \\
3\end{array}$ & $\begin{array}{c}\text { Nível } \\
4\end{array}$ & $\begin{array}{c}\text { Nível } \\
5\end{array}$ & Total \\
\hline $\begin{array}{c}\text { Titulação Docente e Regime de } \\
\text { Trabalho }\end{array}$ & $\mathrm{CH}$ & 1 & 2 & 3 & 14 & 3 & 1 & 24 \\
\hline Produção Científica & $\mathrm{CH}$ & 5 & 8 & 2 & 4 & 5 & 0 & 24 \\
\hline Corpo Técnico-Administrativo & $\mathrm{CH}$ & 6 & 2 & 4 & 10 & 1 & 1 & 24 \\
\hline Experiência Profissional & $\mathrm{CH}$ & 22 & 0 & 1 & 1 & 0 & 0 & 24 \\
\hline Capacitação Docente & $\mathrm{CH}$ & 4 & 9 & 2 & 9 & 0 & 0 & 24 \\
\hline Atuação do Coordenador de Curso & $\mathrm{CH}$ & 16 & 4 & 3 & 1 & 0 & 0 & 24 \\
\hline Filosofia Gerencial & $\mathrm{CE}$ & 1 & 0 & 12 & 8 & 3 & 0 & 24 \\
\hline Sistemas de Informação Acadêmica & $\mathrm{CE}$ & 6 & 6 & 4 & 7 & 1 & 0 & 24 \\
\hline Tecnologia Educacional & $\mathrm{CE}$ & 7 & 4 & 4 & 8 & 1 & 0 & 24 \\
\hline Centro de Serviços Compartilhados & $\mathrm{CE}$ & 18 & 3 & 0 & 3 & $\overline{0}$ & 0 & 24 \\
\hline Infraestrutura & $\mathrm{CE}$ & 0 & 2 & 5 & 17 & 0 & 0 & 24 \\
\hline Responsabilidade Socioambiental & $\mathrm{CR}$ & $\overline{1}$ & 3 & 4 & 14 & 1 & $\overline{1}$ & 24 \\
\hline Acompanhamento do Egresso & $\mathrm{CR}$ & 2 & 13 & 4 & 5 & 0 & 0 & 24 \\
\hline Parceria com Mercado de Trabalho & $\mathrm{CR}$ & 3 & 8 & 7 & 3 & 3 & 0 & 24 \\
\hline Parceria com Centros de Pesquisa & $\mathrm{CR}$ & 13 & $\overline{5}$ & $\overline{1}$ & 4 & 1 & 0 & 24 \\
\hline Imagem Institucional & $\mathrm{CR}$ & 11 & 5 & 0 & 4 & 3 & 1 & 24 \\
\hline Receita & $\mathrm{CF}$ & 3 & 2 & 1 & 18 & 0 & 0 & 24 \\
\hline Controle de Custos & $\mathrm{CF}$ & 20 & 4 & 0 & 0 & 0 & 0 & 24 \\
\hline Previsão de Novos Negócios & $\mathrm{CF}$ & 1 & 11 & 0 & 11 & 1 & 0 & 24 \\
\hline Orçamento & $\mathrm{CF}$ & 5 & 1 & 1 & 17 & 0 & 0 & 24 \\
\hline Descentralização Financeira & $\mathrm{CF}$ & 19 & 2 & 3 & 0 & 0 & 0 & 24 \\
\hline Investimentos & $\mathrm{CF}$ & 3 & 1 & 1 & 17 & 2 & 0 & 24 \\
\hline
\end{tabular}

Fonte: autores (2017).

\subsection{Capital humano docente e atuação técnico-administrativa}

Por exigência do órgão regulador, a titulação docente foi o item que mais esteve presente nos PDIs estudados. Em quase todos os documentos, esse item esteve associado à qualidade de ensino, principalmente em IES que apresentavam um percentual alto de professores com boa titulação. 
Tabela 2 - Direcionadores que abordam o capital humano de cada IES por nível de informação

\begin{tabular}{|c|c|c|c|c|c|c|c|c|c|c|c|c|c|c|c|c|c|c|c|c|c|c|c|c|}
\hline \multicolumn{25}{|c|}{ CAPITAL HUMANO } \\
\hline Tipo de IES & \multicolumn{4}{|c|}{ Universidade } & \multicolumn{4}{|c|}{$\begin{array}{l}\text { Centro } \\
\text { Univ. }\end{array}$} & \multicolumn{16}{|c|}{ Faculdades Isoladas } \\
\hline Direcionadores / IES & A B & $\mathrm{C}$ & & & $\mathrm{F}$ & G & $\mathrm{H}$ & & $\mathrm{J}$ & $K$ & I & M & 1 & $\mathrm{O}$ & & Q & R & & $\mathrm{T}$ & & U & V & $\mathrm{Y}$ & $\mathrm{W}$ \\
\hline $\begin{array}{l}\text { TITULAÇÃO DOCENTE E } \\
\text { REGIME DE TRABALHO }\end{array}$ & 32 & 4 & 5 & & 3 & 3 & 4 & 3 & 3 & 2 & 2 & 3 & 3 & 1 & 3 & 3 & 3 & 3 & 4 & & 3 & 3 & 1 & 0 \\
\hline PRODUÇÃO CIENTÍFICA & 14 & 3 & 7 & 1 & 3 & 3 & 4 & 2 & 4 & 1 & 0 & 2 & 1 & 0 & 4 & 1 & 3 & 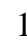 & 0 & & 1 & 1 & 3 & 0 \\
\hline $\begin{array}{l}\text { ATUAÇÃO CORPO } \\
\text { TECNICO- } \\
\text { ADMINISTRATIVO }\end{array}$ & 42 & 3 & 5 & 1 & 3 & 3 & 3 & 3 & 3 & 0 & 0 & 0 & 3 & 0 & 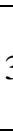 & 2 & 1 & 2 & 3 & & 3 & 0 & 2 & 0 \\
\hline $\begin{array}{l}\text { EXPERIÊNCIA } \\
\text { PROFISSIONAL }\end{array}$ & 00 & 0 & 0 & & 0 & 0 & 0 & & 0 & 0 & 0 & 0 & 0 & 0 & 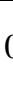 & 0 & 0 & 0 & 0 & & 0 & 0 & 3 & 0 \\
\hline $\begin{array}{l}\text { CAPACITAÇÃO } \\
\text { DOCENTE }\end{array}$ & $\begin{array}{ll}1 & 1\end{array}$ & 3 & 2 & 1 & 3 & 3 & 3 & 3 & 3 & 2 & 1 & 1 & 3 & 0 & 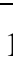 & 0 & 3 & 1 & 0 & & 2 & 1 & 3 & 1 \\
\hline $\begin{array}{c}\text { ATUAÇÃO } \\
\text { COORDENAÇÃO CURSO }\end{array}$ & 20 & 0 & 4 & & 0 & 0 & 0 & & 0 & U & U & U & 1 & 0 & & 0 & 1 & 2 & 0 & & 0 & 1 & 0 & 0 \\
\hline
\end{tabular}

Fonte: autores (2017).

Embora Bittencourt et al. (2010) afirmem que a presença de doutores em uma IES compromete a "sustentabilidade financeira sobretudo no caso das instituições privadas poderia ser comprometida devido ao incremento de sua folha de pagamento", este profissional deve ser visto como um elemento importante de geração de receitas alternativas. O professor doutor pode ser útil tanto na sua capacidade de geração de conteúdos de ensino, como também na captação de recursos advindos de projetos de pesquisa em órgãos públicos e empresas privadas.

Infelizmente, o órgão regulador mantém a mesma proporção de vinte anos atrás, uma exigência mínima de $1 / 3$ de professores com titulação de mestrado e doutorado (BRASIL, 1996). O que na época representava uma importante barreira à entrada na carreira docente, hoje incentiva a falta de qualificação profissional.

Devido ao compromisso das universidades em manter programas de pósgraduação stricto-sensu, a presença de professores doutores é mais relevante lá do que nos centros universitários e faculdades isoladas, desobrigadas de tais investimentos. A alternativa de prerrogativa de qualidade de ensino, para essas IES, é a ênfase de docentes vinculados com o mercado de trabalho.

No PDI da IES H estudada, essa valorização da experiência profissional se dá explicitamente, considerando que “apesar de entender como desejável a titulação mínima de mestre para os docentes desta instituição, sabe-se que, no entanto, em algumas áreas, o mercado consagra profissionais competentes e especializados". 
A experiência profissional do docente também pode ser considerada um item pertinente ao capital intelectual, uma vez que a IES pode dispor de ementas curriculares atualizadas as necessidades do mercado de trabalho, como os cursos de gestão por exemplo. Silva e Lima (2011) apontaram a diferença entre o professoracadêmico e o profissional-professor em uma IES:

Professor-acadêmico - Professor com formação acadêmica com titulação adequada pós-graduação stricto sensu, mestrado ou doutorado, tendo tempo de dedicação para o corpo discente.

Profissional-professor - aquele que antes de ser professor, atua no mercado e não tem dedicação integral e exclusiva para o corpo discente. A sua formação geralmente é em Master of Business Administration (MBA), paradoxalmente classificado no Brasil como um nome de fantasia para cursos de pós-graduação lato sensu (Resolução CNE/CES Nº 1, DE 3 DE ABRIL DE 2001).

A atuação dos funcionários administrativos também é um item importante para a geração de valor para uma IES. No exame dos PDIs, a ênfase sobre o ambiente de trabalho é destacado entre as faculdades ("O Corpo TécnicoAdministrativo demonstrou um grau de satisfação positivo o relacionamento com chefe direto, coordenadores de curso e com a Direção e Vice-Direção”- IES B). Já para as Universidades, o foco está na apresentação da qualificação desta mão-deobra informando o nível de instrução destes colaboradores.

Convém destacar que entre as IES controladas por grupos empresariais existe uma diferença entre a percepção de valor agregado pelos funcionários que atuam na atividade-meio (recursos humanos, marketing, finanças, comercial, etc) e os que atuam na atividade-fim, com atuação restrita ao atendimento a alunos e a manutenção do imobilizado nos diferentes campi.

Quanto a capacitação profissional praticada pelas IES, elas são diferenciadas para os docentes e funcionários técnicoadministrativos. Entretanto, nos PDIs analisados esta capacitação está concentrada no cumprimento de cláusulas sindicais, as quais incluem a concessão de bolsa integral para funcionários administrativos e docentes e a redução da jornada de trabalho sem afetar a carga horária para docentes em fase de elaboração da dissertação/tese. Porém, cabe destacar a IES D que concede "licença sabática por um ano, após um período de pelo menos seis anos de atividade na IES, contados a partir do ingresso do professor no quadro docente ou de sua última licença sabática”. 
A IES C apresenta uma política de programa de remuneração variável que contempla um percentual dos docentes que se destacarem pelo seu desempenho, atendendo a critérios de cumprimento de rotinas operacionais e acadêmicas.

A produção científica docente é vista como um elemento gerador de valor para Universidades, uma vez que elas possuem a obrigatoriedade de manutenção de programas stricto sensu. Desta forma, incentivam a produção de revistas acadêmicas classificadas pelos extratos da CAPES, para algumas IES, o financiamento para participação de apresentação de artigos científicos é concedido.

Para as IES de menor porte, como os centros universitários e faculdades isoladas, não existe no exame dos PDIs um incentivo direto para a produção científica. No entanto, a crescente exigência do órgão regulador para que as IES desenvolvam programas de iniciação científica, podem criar sinergias positivas para a produção científica docente.

Como exceção a esta análise, destaca-se a IES J, que em seu PDI prevê que sejam concedidos incentivos financeiros aos professores que forem autores e coautores em publicações acadêmicas. Esta remuneração por publicação, varia de acordo com o status internacional de cada artigo.

Não foi verificada nos PDIs a importância do coordenador de curso como direcionador relevante de capital humano. Através da análise de suas funções descritas em alguns PDIs, o coordenador de curso limita-se ao papel de repassar orientações pertinentes à gestão da IES para os docentes do curso, bem como atuar no atendimento aos alunos.

\subsection{Capital estrutural: da infraestrutura adequada às condições de oferta à filosofia gerencial}

Por exigência do roteiro de elaboração dos PDIs estabelecido pelo órgão regulador, as condições de infraestrutura devem ser detalhadas pelas IES. Por isso, foi o item mais identificado e comprovado na análise dos PDIs. Contudo, a geração de valor dessa infraestrutura como elemento de capital intelectual só se faz necessária caso agregue sinergia aos cursos gerenciados. 
Tabela 3 - Direcionadores que abordam o capital estrutural de cada IES por nível de informação

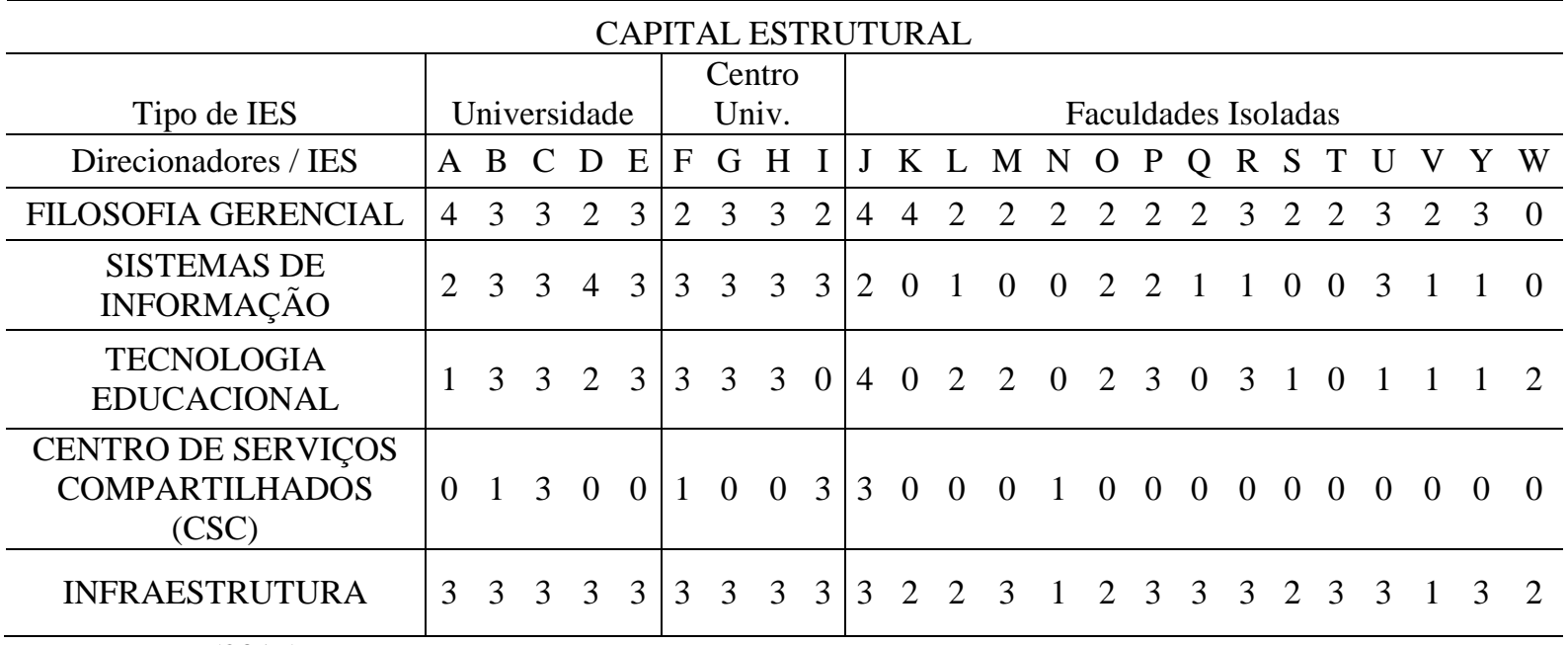

Fonte: autores (2017).

A IES C apresenta uma vasta listagem de laboratórios para serem utilizados pelos seus diferentes cursos da área de saúde: Anatomia, Morfologia, Microbiologia, Fisiologia, Bioquímica e de Atividades. A IES B dispõe de um Laboratório de Genética que pode contribuir para experiências que podem ser relatadas com fins de produção científica dos docentes. Além disto, em todas as IES que possuem cursos de Medicina, o PDI aponta a existência de Hospitais Universitários próprios ou conveniados.

A estrutura das salas de aula é um diferencial contidas nos PDIs. Em IES que possuem estudantes com perfil de uma faixa de renda mais alta - como as IES J e D - as condições de sala de aula constituem um diferencial, sendo todas equipadas com data-show, além de uma quantidade satisfatória de auditórios para a realização de eventos.
Em IES que possuem um grande número de campi, tendem a apresentar melhores condições de oferta em suas salas de aula e bibliotecas, favorecidos pelos ganhos advindos de economia de escala om as compras centralizadas. A aquisição de equipamentos de informática e softwares também são favorecidos por esta economia de escala.

Tais investimentos em informática podem ter dois impactos para a geração de valor em uma IES : qualidade de seus Sistemas de Informação e ganhos obtidos com produtos e serviços que envolvem a tecnologia educacional - como o EAD. Os sistemas de informação podem favorecer a gestão da IES - com a criação de um Centro de Serviços Compartilhados (CSC) como ocorre na IES C - e também a qualidade da prestação de serviços de informações acadêmicas ao aluno, onde em algumas IES já dispõem de aplicativos para telefones celulares, nos quais os alunos podem 
acompanhar as suas notas e requerimentos administrativos.

A existência deste CSC se faz presente apenas na IES $\mathrm{C}$, o que não significa que seja irrelevante quanto a importância de criação de valor. Pelo contrário, demonstra que é um caminho a ser percorrido para que as demais alcancem uma melhor performance de gestão.

Quanto a tecnologia educacional, o Ensino a Distância (EAD) torna-se um diferencial para a gestão acadêmica das IES. Nos PDIs analisados, todas as Universidades possuem já possuem esta modalidade ao contrário do quadro observado nos PDIs das faculdades onde quase a metade não oferta tal serviço.

Dada esta dificuldade de articular um EAD que resulte em capilaridade em número de alunos e ganhos com escala, as IES de menor porte poderiam se articular através de um consórcio que possibilite a implementação desta modalidade em suas unidades.

A filosofia gerencial se faz presente em todas as IES, entretanto diferenciam-se de acordo com os PDIs estudados. A missão de uma IES pode estar direcionada ao mercado de trabalho, conforme a IES J "Servir aos atuais e futuros líderes, executivos e profissionais de empresas privadas, instituições governamentais e organizações sem fins lucrativos por meio do oferecimento de oportunidades de ensino, pesquisa e extensão de excelência”.

Neste mesmo sentido de uma IES voltada para a capacitação do aluno para o mercado de trabalho, o PDI da IES G afirma que a sua missão é a de "formar profissionais éticos e competentes para atuarem no mercado de trabalho, oferecendo serviços educacionais acessíveis e de qualidade, valorizando a empregabilidade dos egressos e contribuindo para o desenvolvimento sustentável da sociedade carioca e do País".

Este compromisso com a formação de mão de obra qualificada chega a ser específica de um setor conforma a missão da IES K que é a de "promover - com foco nas cadeias de valor têxtil e de confecção o desenvolvimento sustentável e a competitividade da indústria brasileira.".

Entretanto, a missão da IES pode ser direcionada para a sociedade como um todo, dentro de valores religiosos. A IES D, de origem confessional focada para a "a produção e transmissão do saber, baseandose no respeito aos valores humanos e na ética cristã, visando, acima de tudo, ao benefício da sociedade”. A IES L também de origem confessional atribui a missão da IES de forma a "promover a formação integral das pessoas, oferecendo educação de excelência com compromisso social". 
Além da análise da missão de cada IES, a filosofia gerencial está presente na apresentação do planejamento estratégico da IES. As IES K e C apresentam perspectivas de gestão muito próximas ao modelo do Balanced Scorecard, embora somente esta última apresente com detalhes seu plano estratégico.

\subsection{Capital responsabilidade socioambiental e parcerias estratégicas}

A responsabilidade socioambiental foi o item mais visível do capital relacional na análise dos PDIs. Entretanto, isso ocorre em função das exigências da legislação sobre condições mínimas de acesso para pessoas diferenciadas (visão, audição, locomoção). Tais obrigações se traduzem em iniciativas de responsabilidade social praticadas pelas IES. Entretanto, tal atitude não é restrita às IES. Ainda existe no Brasil uma área cinzenta no meio empresarial sobre o que seria uma iniciativa da organização ou uma imposição do órgão regulador.

Tabela 4 - Direcionadores que abordam o capital relacional de cada IES por nível de informação

\begin{tabular}{|c|c|c|c|c|c|c|c|c|c|c|c|c|c|c|c|c|c|c|c|c|c|c|c|c|c|}
\hline \multicolumn{26}{|c|}{ CAPITAL RELACIONAL } \\
\hline Tipo de IES & \multicolumn{4}{|c|}{ Universidade } & & \multicolumn{4}{|c|}{$\begin{array}{l}\text { Centro } \\
\text { Univ. }\end{array}$} & \multicolumn{16}{|c|}{ Faculdades Isoladas } \\
\hline Direcionadores / IES & A & $\mathrm{B}$ & 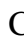 & D 1 & & F & G & $\mathrm{H}$ & & $\mathbf{J}$ & K & $\mathrm{L}$ & M & $\mathrm{N}$ & $\mathrm{O}$ & $\mathrm{P}$ & $\mathrm{Q}$ & $\mathrm{R}$ & $S$ & S & $\mathrm{T}$ & $\mathrm{U}$ & $\mathrm{V}$ & Y & $\mathrm{W}$ \\
\hline $\begin{array}{l}\text { RESPONSABILIDADE } \\
\text { SÓCIO AMBIENTAL }\end{array}$ & 3 & 3 & 4 & 5 & & 32 & 3 & 3 & & 3 & 3 & 2 & 3 & 1 & 2 & 1 & 3 & 3 & 1 & 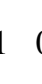 & 0 & 3 & 3 & 2 & 1 \\
\hline $\begin{array}{c}\text { ACOMPANHAMENTO } \\
\text { DO EGRESSO }\end{array}$ & 0 & 1 & 3 & 1 & & 13 & 3 & 1 & & & 2 & 3 & 1 & 1 & 2 & 1 & 1 & 1 & 1 & 1 & 0 & 1 & 2 & 3 & 1 \\
\hline $\begin{array}{c}\text { PARCERIA MERCADO } \\
\text { DE TRABALHO }\end{array}$ & 1 & 3 & 4 & 4 & & 12 & 2 & 3 & & 4 & 0 & 0 & 2 & 1 & 2 & 1 & 1 & 1 & 1 & 2 & 0 & 2 & 2 & 1 & 2 \\
\hline $\begin{array}{l}\text { PARCERIA CENTROS DE } \\
\text { PESQUISA }\end{array}$ & 0 & 3 & 3 & 4 & & 10 & 0 & 1 & 0 & J & 0 & 1 & 2 & 0 & 0 & 0 & 0 & 0 & ) & ) & 1 & 0 & 0 & 1 & 0 \\
\hline $\begin{array}{c}\text { IMAGEM } \\
\text { INSTITUCIONAL }\end{array}$ & 0 & 3 & 4 & 5 & & 1 & 4 & 3 & & & 0 & 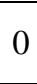 & 0 & 0 & 0 & 1 & 0 & 1 & 1 & 0 & 0 & 3 & 0 & 1 & 0 \\
\hline
\end{tabular}

Fonte: autores (2017).

De acordo com a Tabela 4, é nas universidades que encontramos mais detalhes sobre iniciativas de interação com a sociedade no que tange à responsabilidade social. A IES C classifica as suas ações de responsabilidade socioambiental como: cidadania, cultura e meio ambiente. A IES $\mathrm{N}$ possui uma subreitoria para assuntos comunitários, responsável pela “coordenação do levantamento e integração dos diversos projetos de Extensão e Responsabilidade Social"

Algumas IES incluíram nos seus PDIs projetos sociais de governo como iniciativas de responsabilidade social, tais como o PROUNI e o FIES. Apesar da sua 
relevância, tais programas não são custeados pelas IES. Pelo contrário, constituíram nos últimos anos uma fonte importante de repasse de recursos, aumentando as suas receitas financeiras.

Face à análise das parcerias estratégicas, o estudo dos PDIs permitiu classificar em três grupos: estágios, convênios com órgãos governamentais, empresas e de classe voltadas para o mercado de trabalho e articulação com centros de pesquisa.

Apesar de constar como importante e obrigatório para muitos cursos, grande parte das faculdades isoladas não dispõem de um setor específico que acompanhe a inserção de seu aluno no mercado de trabalho. Esta atividade é delegada ao coordenador de curso. Por outro lado, a IES D organiza anualmente um evento com grande repercussão na mídia "que envolve empresas do setor produtivo e traz inúmeras possibilidades de diálogo entre a universidade e o mundo empresarial". A IES G semestralmente organiza uma feira de carreiras com informação profissional.

Em relação aos convênios realizados com empresas, estes são de extrema importância para a visibilidade da IES na sociedade. Mesmo diante desta importância, grande parte das IES apenas mencionam a necessidade de estabelecer convênios e parcerias, sem que de fato comprove na prática o que vem sendo realizado. Isto sem aprofundar os convênios, que embora tenham sido assinados não refletiu de fato a sua efetivação. De fato, através da análise dos PDIs, apenas as IES com maior número de alunos apresentam um setor de convênios estruturado.

Quanto a articulações com centros de pesquisa, apenas as universidades que dispõem de programas de pós graduação stricto sensu executam esta parceria. Mesmo assim, esta combinação está pendente de financiamento de órgãos de fomento públicos como a CAPES, CNPQ e FINEP.

A questão da Imagem Institucional foi detectada apenas na análise de PDIs de IES que possuem uma quantidade significativa de alunos matriculados em programas de pós-graduação. No Brasil, o foco no fortalecimento da marca é um fator de atração de alunos em programas de pósgraduação de lato sensu.

Embora seja um tema polêmico, a questão do foco no cliente também não foi abordada ênfase no exame dos PDIs. Apenas uma IES afirmou que o aluno e fato era o cliente de uma instituição de ensino. Outras citações apenas mencionaram o termo clientela, no sentido que cursos estão disponíveis para uma clientela pertencente a uma determinada região geográfica. 
De forma a contemplar essas diferentes visões, foi apresentado um item de acompanhamento do egresso de maneira capaz de identificar formas de aproximação da universidade com seus ex-alunos, seja no âmbito profissional, seja no acadêmico.

\subsection{Capital financeiro: faturamento, investimentos e novos negócios}

Pelas regras de preenchimento dos PDIs, as IES devem apresentar suas projeções de resultado do exercícios e planos de investimentos. Apesar de grande parte das IES apresentarem suas projeções, poucas as comentam. A obrigatoriedade de apresentar os números sem uma explicação posterior levou à identificação de incoerências em alguns PDIs.

$\underline{\text { Tabela } 5 \text { - Itens que abordam o capital financeiro de cada IES por nível de informação }}$

\begin{tabular}{|c|c|c|c|c|c|c|c|c|c|c|c|c|c|c|c|c|c|c|c|c|c|c|c|c|c|c|c|}
\hline \multicolumn{28}{|c|}{ CAPITAL FINANCEIRO } \\
\hline Tipo de IES & \multicolumn{5}{|c|}{ Universidade } & \multicolumn{5}{|c|}{$\begin{array}{l}\text { Centro } \\
\text { Univ. }\end{array}$} & \multicolumn{17}{|c|}{ Faculdades Isoladas } \\
\hline Direcionadores / IES & A & A $B$ & $\mathrm{C}$ & $\mathrm{D}$ & $\mathrm{E}$ & $\mathrm{F}$ & G & l & $H$ & I & $\mathrm{J}$ & $\mathrm{K}$ & $\mathrm{L}$ & M & $\mathrm{N}$ & $\mathrm{O}$ & $\mathrm{F}$ & & Q & $\mathrm{R}$ & S & $\mathrm{T}$ & $\mathrm{U}$ & $\mathrm{V}$ & $Y$ & $\mathrm{~V}$ & W \\
\hline RECEITA & 0 & 3 & 3 & 0 & & 3 & 3 & & 3 & 3 & 3 & 3 & 3 & 1 & 3 & 3 & 3 & & 3 & 3 & 3 & 3 & 3 & 1 & 3 & 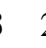 & 2 \\
\hline CONTROLE DE CUSTOS & 0 & 1 & 0 & 0 & 0 & 1 & 1 & & 0 & 0 & 0 & 1 & 0 & 0 & 0 & 0 & c & & 0 & 0 & 0 & 0 & 0 & 0 & 0 & ( & 0 \\
\hline $\begin{array}{l}\text { PREVISÃO NOVOS } \\
\text { NEGÓCIOS }\end{array}$ & 1 & 3 & 3 & 3 & & 1 & 3 & & 3 & 1 & 4 & 3 & 3 & 3 & 1 & 1 & 1 & & 3 & 3 & 1 & 1 & 3 & 1 & 1 & & 0 \\
\hline ORÇAMENTO & 0 & 3 & 3 & 0 & 0 & 3 & 3 & & 3 & 3 & 3 & 0 & 3 & 1 & 3 & 3 & 3 & & 3 & 3 & 3 & 3 & 3 & 2 & 3 & 3 & 0 \\
\hline $\begin{array}{c}\text { DESCENTRALIZAÇÃO } \\
\text { FINANCEIRA DA } \\
\text { GESTÃO }\end{array}$ & 1 & 2 & 0 & 0 & 1 & 0 & 0 & & 0 & 0 & 2 & 0 & 0 & 0 & 0 & 0 & c & & 0 & 0 & 0 & 0 & 0 & 2 & 0 & ) & 0 \\
\hline $\begin{array}{c}\text { INVESTIMENTOS } \\
\text { (CAPEX) }\end{array}$ & 1 & 3 & 3 & 3 & & 1 & 3 & & 3 & 4 & 4 & S & 4 & 2 & 3 & 3 & & & o & 3 & 3 & 3 & 3 & 0 & & & 0 \\
\hline
\end{tabular}

Fonte: autores (2017).

As receitas projetadas informadas não detalharam se estas eram oriundas de pagamento de mensalidades de alunos ou de repasses de programas governamentais (PROUNI, FIES). Tal informação é de fundamental relevância para compreender a sustentabilidade financeira do setor, que pode ter um impacto negativo se estiver alavancado com tais repasses.

As IES A, D e E não apresentaram projeção de suas receitas e resultados, reservando apenas a intenção de sua política de ampliação de investimentos e capacidade de novos negócios.

A falta de detalhamento das informações financeiras fez com que apenas três IES informarem que existe a autonomia em relação a mantenedora. Quanto ao controle de custos, apenas quatro IES se preocuparam com a utilização eficiente de seus recursos.

Outra observação que dificulta a análise financeira das IES é a desconexão com as informações contidas ao longo do 
PDI. Se a IES se compromete a realizar investimentos na compra de novos equipamentos e laboratórios, este aumento de gastos não se reflete na projeção apresentada.

A falta de compromisso com investimentos em treinamento, pesquisa e extensão também são observados nas projeções financeiras apresentadas, contradizendo as promessas descritas nos PDIs. A IES N se comprometeu a "ampliar treinamento interno do pessoal técnicoadministrativo" e "aprimorar o corpo docente", no entanto disponibiliza apenas $\mathrm{R} \$ 3.000,00$ / ano em seu plano financeiro para capacitação.

A IES U assumiu compromisso de aumentar o investimento em pesquisa e extensão. De fato, no plano financeiro este crescimento está previsto de um aumento de $\mathrm{R} \$ 600,00$ ao ano para $\mathrm{R} \$ 2.800,00$ ao final do PDI. São valores ainda irrisórios para o que a IES se propõe a executar.

Por fim, a preocupação com a viabilidade de novos negócios é uma latente preocupação de universidades e centros universitários, preocupados com a criação de novos cursos e unidades. Em seus planos de expansão, não só informam o que já foi executado (novos campi e reconhecimento de cursos), mas também apresentam a intenção de protocolar novos cursos e estudar a abertura de novas unidades. Essas iniciativas podem levar à concentração do setor educacional.

\section{CONSIDERAÇÕES FINAIS}

A partir da análise das informações coletadas, verifica-se que o PDI é uma importante ferramenta de gestão, por apresentar os itens necessários para a geração de valor em uma IES. No modelo atual de apresentação de PDI, verifica-se uma hierarquia de criação de valor para as IES através do detalhamento de determinados direcionadores como titulação docente e regime de trabalho (capital humano), responsabilidade socioambiental (capital relacional), infraestrutura (capital estrutural), receita (capital financeiro), orçamento (capital financeiro) e investimentos (capital financeiro). Entretanto, para que se obtenha êxito, tais itens precisam ser gerenciados adequadamente, respeitando as características de cada IES.

Acredita-se que boa parte das informações de nível 1 prestadas pelas IES nos respectivos PDIs seja apenas de intenções por parte da sua gestão, uma vez que não estão articuladas com o plano financeiro contido no PDI. Vimos anteriormente o descasamento das metas informadas acerca de treinamento e apoio à 
pesquisa com as informações financeiras referentes a esse item.

Um maior grau de detalhamento de informações relativas ao capital intelectual das universidades em relação às demais formas de organização pode ser explicada por duas razões. A primeira decorre das exigências apresentadas pelo órgão regulador para que uma universidade atue, em especial quanto ao investimento em pesquisa. A segunda, que pode ser reflexo da primeira, dá-se pela vantagem de escala que permite que à universidade gerar mais ativos tangíveis e intangíveis em relação aos centros universitários e às faculdades isoladas.

No entanto, faculdades isoladas destinadas a um público-alvo oriundos das classes A e B possuem componentes de nível 4 e 5 de capital intelectual e financeiro na mesma proporção que as universidades. Isso se justifica pelas rigorosas exigências de qualidade de ensino por parte da clientela.

Dessa forma, a análise dos PDIs ratificou que esse tipo de documento contém a maioria dos itens capazes de gerar valor para uma IES privada. Todavia, em faculdades isoladas, o PDI foi incapaz de identificar elementos como descentralização financeira (capital financeiro), controle de custos (capital financeiro), experiência profissional do docente (capital humano) e centro de serviços compartilhados (capital estrutural).

É importante ressaltar que esses direcionadores de valor podem ser alterados ao longo do tempo, não apenas para as instituições de ensino, mas também para o estudo do capital intelectual. A própria teoria baseada em valor sinaliza essa transformação nos últimos vinte anos (BARNEY, 1991, 2001, 2011)

Para estudos futuros, uma análise sobre os formulários de referência de empresas educacionais poderia ser realizada de forma a complementar as informações contidas no PDI. Uma pesquisa junto a gestores de IES privadas também se faz necessária de forma a checar a utilização do PDI como ferramenta auxiliar de gestão. 


\section{REFERÊNCIAS}

AWAD, F. M. A estruturação e a gestão do capital intelectual na. Universidade de Passo Fundo : uma análise a partir do modelo de navegador de Stewart. Dissertação de Mestrado. UNIJUI. Ijuí, 2010

BARNEY, J. B. Firm Resources and Sustainable Competitive Advantage. Journal of Management. p. 99-120, 1991

BARNEY, J.B.; WRITGH, M; KETCHEN, D. The Resource-Based View of the firm: ten years after 1991. Journal of Management. 2001

BARNEY, J.B. The future of Resource-Based Theory: revitalization or decline? Journal of Management. 2011.

BITTENCOURT, H. R.; VIALI, L.; RODRIGUES, A. C. M.; CASARTELLI, A. O. Mudanças nos pesos do CPC e seu impacto nos resultados de avaliação em universidades federais e privadas. Avaliação (Campinas), Sorocaba, v. 15, n. 3, p. 147-166. 2010.

BOLAN, V; MOTTA, M.V. Responsabilidade Social no Ensino Superior. Revista de Educação. v.10, n. 10. 2007

BRASIL. Lei de Diretrizes e Bases da Educação Nacional. Lei número 9.394, 20 de dezembro de 1996.

CALDERÓN, A. I. Responsabilidade social universitária: contribuições para o fortalecimento do debate no Brasil. Revista da Associação Brasileira de Mantenedoras de Ensino Superior, Brasília, v. 24, n.36, p.7-22, 2006.

CASTRO, A. Gestão Financeira : a sustentabilidade financeira e a interação acadêmica nas instituições de ensino superior, in Colombo S.S Gestão Universitária : os caminhos para a excelência. Porto Alegre: Penso,2013

CÓRCOLES, Y. R. Intellectual Capital management and reporting in European higher education institutions. Intangible Capital v.9, n.1, p 1-19, 2013

CRANFIELD, D. J.; TAYLOR, J. Knowledge Management and Higher Education: A UK Case Study. Electronic Journal of Knowledge Management v.6, n.2, p. 85-100, 2008. 
DZINKOWSHI, R. The measurement and management of intellectual capital. Management Accounting, Fevereiro, p.32-36, 2000

FEDERAL MINISTRY OF EDUCATION, SCIENCE AND CULTURE Verordnung ueber die Wiessenbilanz (Wissensbilanz-Verordnung-WBV), BGB1, II Nr.63/2006, 2006.

FEDERAL MINISTRY OF EDUCATION, SCIENCE AND CULTURE Verordnung ueber die Wiessenbilanz (Wissensbilanz-Verordnung-WBV), BGB1, II Nr.63/2006, 2010.

FRANCISCO, T. H. A. A contribuição das core competence no desenvolvimento das habilidades cognitivas de alto nível no corpo docente de uma IES privada. Revista Electrónica de Investigación y Docencia ( REID ), n. 5, p. 69-94, 2011

GIANOTTI, S. S. C. Avaliação estratégica: um modelo de avaliação institucional integrada à avaliação estratégica de instituições de ensino superior. Porto Alegre: UFRS, 2004.

GUTHRIE, J.; PETTY, R; K. YONGVANICH F.; RICCERI, F. Using content analysis as a research method to inquire into intellectual capital reporting", Journal of Intellectual Capital, v.5, n.2, p.282-293, 2004.

HÉKIS, H. R. Avaliação e monitoramento dos projetos pedagógicos dos cursos de graduação: $O$ caso da Faculdade Estácio de Sá de Santa Catarina. X Colóquio Internacional sobre Gestão Universitária na América do Sul. Anais...Mar del Plata: 2010

HLANDCHANKO, M. Balanced Scorecard - a strategic management system of the higher education institution. International Journal of Educational Management, v. 29, n. 2, p. 167176,2015

HOLANDA JR., A.; FARIAS, I. Q.; GOMES, O. A. O valor do cliente como elemento de marketing para instituições de ensino superior. BASE - Revista de Gestão e Contabilidade da Unisinos, vol. 3, n. 2, p. 102-111, 2006.

INEP. Censo da Educação Superior 2015. MEC. 2016.

LUZ FILHO. S.S. Gestão em Instituições de Ensino Superior.Tese (Doutorado em Engenharia e Gestão do Conhecimento) - Universidade Federal de Santa Catarina, Centro Tecnológico, Programa de Pós-Graduação em Engenharia e Gestão do Conhecimento, Florianópolis, 2016 
MACHADO, E. Capital intelectual : um estudo nas universidades ibéricas. Editorial Penafiel. 2008.

MAURER, S. A. S. Gestão do Capital Intelectual como estratégia competitiva em Organizações Intensivas em Conhecimento: O caso da Unijui. Dissertação Mestrado. UNIJUÍ, Ijuí, 2008

RAMÍREZ CÓRCOLES, Y. Importance of intellectual capital disclosure in Spanish universities. Intangible Capital, v. 9; n.3, p. 931-944, 2013

RAMÍREZ Y. \& GORDILLO S. Recognition and measurement of intellectual capital in Spanish universities, Journal of Intellectual Capital,Vol. 15 Iss 1 pp. 173 - 188, 2014.

TACHIZAWA, T.; ANDRADE, R. O. B. Gestão de instituições de ensino - 4 ed. Rio de Janeiro: Editora FGV. 2006

Resolução CNE/CES Nº 1, DE 3 DE ABRIL DE 2001

REIS, A. L. BANDOS, M. F. C.. A responsabilidade social de instituições superior: uma reflexão sistêmica tendo em vista o desenvolvimento. Revista Gestão \& Conhecimento. Edição especial. 2012.

REIS, E. ; REIS, E. Sistemas de informação e tomada de decisão na gestão universitária: um olhar nos indicadores de desempenho de uma instituição de ensino superior. XIII Coloquio de Gestión Universitaria en Américas. Anais...Buenos Aires : 2013.

RIZZO, C. Gestão estratégica do aluno / cliente nas instituições de ensino superior privadas: um estudo de caso. Tese de Doutorado. USP. São Paulo. Brasil. 2010

ROOS, J., ROOS, G., DRAGONETTI, N.C. e EDVINSON, L.; Intellectual capital: Navigating the new business landscape. Macmillan Press, 1997.

SAINT-ONGE, H.; ARMSTRONG, C. The conductive organization building beyond sustainability. London: Oxford Elsevier. 2004.

SILVA, C. M. M.; FERREIRA, D.; CAVALCANTI NETO, S. \& REZENDE, J. F. C. . A importância do Capital Intelectual e do Balanced Scorecard na gestão do ensino superior: a perspectiva dos coordenadores de cursos de graduação em Administração. XXXVIII 
Encontro Nacional da Associação Nacional de Pós-Graduação e Pesquisa em Administração. Anais...Rio de Janeiro: 2014

SILVA, J.U.; LIMA, D. Profissional professor e professor profissional: análise das categorias de docentes no Ensino Superior em São Paulo nos cursos de ciências da computação. Revista de Inovação Tecnológica, São Paulo, v. 1, n.1, p. 28-40, 2011.

SILVESTRI, A.AND VELTRI S, The intellectual capital report with universities: comparing experiences, University of Oradea, Economic Science Series, v. 20, p. 618-624,2011.

SIRVANCI, M. Are the students the true customers of higher education? Quality Progress, v.29, n.10 p. $99-102,1996$.

STEWART, Thomas. Capital Intelectual: a nova vantagem competitiva das empresas, $17^{\mathrm{a}}$ edição. Rio de Janeiro: Elsevier Editora. 1998

SULLIVAN, P. Value-driven intellectual capital: how to convert intangible corporate assets into market value. New York: John Wiley\& Sons. Ilc. 2000

VERGARA, S.C.; AMARAL M.M. Reflexões sobre o conceito 'aluno-cliente' de instituições de ensino superior brasileiras. XXXIV Encontro Nacional da Associação Nacional de Pós-Graduação e Pesquisa em Administração. Anais... Rio de Janeiro: 2010

VERGARA, S. C. Projetos e relatórios de pesquisa em Administração. $8^{\mathrm{a}}$. ed. São Paulo: Atlas, 2007. 